\title{
Impact of China's zero mark-up drug policy on drug cost of NCDs' outpatients: an interrupted time series analysis
}

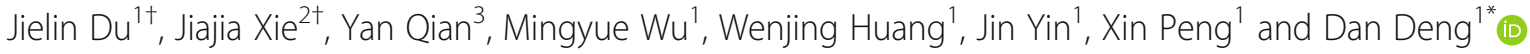

\begin{abstract}
Background: China proposed the Zero Markup Drug Policy (ZMDP), which popularized in tertiary hospitals across the country in 2017, to control drug expenditures' rapid growth further and reduce the public's medical burden. This study aims to evaluate the impact of ZMDP on the drug cost of chronic disease outpatients in the tertiary hospital in Chongqing.
\end{abstract}

Methods: We collected and described the drug-cost data for outpatients with chronic diseases in a Chongqing's tertiary hospital from 2015 to 2019. The instantaneous and long-term changes of the outpatient volume and average drug cost after the ZMDP were evaluated using interrupted time series (ITS). We also analyzed the policy's impact under the stratification of gender, age, and basic medical insurance types.

Results: A total of 350,848 outpatients were collected from January 2015 to February 2019. After the ZMDP, the outpatient volume for diabetes, hypertension, and coronary heart disease (CHD) all showed a downward trend, with a decrease of $53.04(P=0.012), 142.19(P<0.01)$ and $12.16(P<0.001)$ per month. Simultaneously, the average drug cost decreased by 4.44 yuan $(P=0.029), 5.87$ yuan $(P<0.001)$ and 10.23 yuan $(P=0.036)$ per month, respectively. By gender, the average drug cost of diabetes in males had the most considerable instantaneous change, reducing by 51.21 yuan $(P=0.017)$; the decline of $\mathrm{CHD}$ in women is the most obvious, with an average monthly decrease of 12.51 yuan $(P<0.001)$. By age, the instantaneous change of CHD was the greatest for those older than 65 years old, with a decrease of 102.61 yuan $(P=0.030)$. CHD in $46-65$ years old showed the most significant reduction, with an average monthly decline of 11.70 yuan $(P<0.01)$. BMIUE's hypertension had the most considerable instantaneous change, which decreased 59.63 yuan $(P=0.010)$. BMIUE's CHD showed the most apparent downward trend, with an average monthly decrease of 10.02 yuan $(P=0.010)$.

Conclusion: The ITS analysis is an effective method of health policy evaluation. The implementation of the ZMDP can reduce the drug cost for chronic disease outpatients in the tertiary hospital and their economic burden. Follow-up policies still require targeted price adjustments in the health service system to adjust the drug costeffectively.

Keywords: Zero mark-up drug policy, Interrupted time series, Chronic noncommunicable diseases, Policy evaluation, China

\footnotetext{
* Correspondence: 100079@cqmu.edu.cn

${ }^{\dagger}$ Jielin Du and Jiajia Xie are contributed equally to this work and should be regarded as co-first authors.

${ }^{1}$ School of Public Health and Management, Chongqing Medical University, Chongqing, China

Full list of author information is available at the end of the article
}

(C) The Author(s). 2021 Open Access This article is licensed under a Creative Commons Attribution 4.0 International License, which permits use, sharing, adaptation, distribution and reproduction in any medium or format, as long as you give appropriate credit to the original author(s) and the source, provide a link to the Creative Commons licence, and indicate if changes were made. The images or other third party material in this article are included in the article's Creative Commons licence, unless indicated otherwise in a credit line to the material. If material is not included in the article's Creative Commons licence and your intended use is not permitted by statutory regulation or exceeds the permitted use, you will need to obtain permission directly from the copyright holder. To view a copy of this licence, visit http://creativecommons.org/licenses/by/4.0/ The Creative Commons Public Domain Dedication waiver (http://creativecommons.org/publicdomain/zero/1.0/) applies to the data made available in this article, unless otherwise stated in a credit line to the data. 


\section{Background}

Since 1954, China proposed a drug mark-up policy that allowed medical and health institutions at and above the county level to sell drugs at a rate that did not exceed $15 \%$ of the drug's actual per-unit purchase price [1]. This policy aims to remedy insufficient compensation in public hospitals and maintain their survival and development. The drug mark-up policy has played a positive role in improving hospital operations during Chinese public hospitals' development process. However, the pharmaceutical and healthcare fields' development for decades has found that the drug mark-up policy has led to profit-seeking behavior in hospitals to a certain extent [2]. It has also led to a series of problems, including an increasing medication burden for patients, a high total cost for medical treatment, and a gradual increase in the tension between doctors and patients [3]. Drug expenditure per capita has grown rapidly, and drug revenue has become the primary funding source for public hospitals. In 2008, drug expenditures accounted for a staggering $42.67 \%$ of total health care expenditures [4]. Reducing the cost of medicine is one of the keys to solving the problem of increasing medical costs caused by the excessive growth of drug costs [5].

In 2009, China launched its essential medicine plan and started a new round of medical and healthcare reforms [6]. The Zero Mark-up Drug Policy (ZMDP), as a necessary part of the essential drug plan, has been implemented in a step-wise manner beginning with primary medical and health institutions. The plan's core goal is to compensate for decoupling prescription writing and drug sales, thereby reducing the pursuit of intermediate drug benefits and ultimately reducing the public's medical burden [7]. In 2017, the PRC's State Council required nationwide public hospitals to abolish drug mark-up fees (except Chinese herbal medicines) before September 30. To date, all public hospitals across the country have eliminated drug mark-ups. Since the implementation of ZMDP, research on its effectiveness evaluation has become a hot topic. Some studies showed that ZMDP is an effective intervention that can suppress the increase in cost $[2,6]$. However, some argue that the impact of ZMDP on drug-related spending and use in public hospitals is not significant [8].

The ZMDP plays an important role in reducing the drug cost of chronic noncommunicable diseases (chronic diseases, NCDs), such as diabetes, hypertension, coronary heart disease (CHD) and cancer [9]. NCDs seriously threaten the physical and mental health of people around the world because of their high morbidity, high mortality, long-term nature, complex etiology and longterm medication [10]. It is a common and significant public health problem worldwide. NCDs ranked third on the WHO's list of global health threats in 2019 [11].
Similarly, the proportion of deaths due to NCDs in China may be as high as $86.6 \%$, which is much higher than the global level, and the number of patients with NCDs is increasing [12]. NCDs' clinical characteristics, such as difficulty estimating their progress and an inability to cure the majority of them, mean that most patients need long-term or even lifelong medications [9]. Therefore, NCD drug expenses account for a large proportion of medical insurance expenses. Medical expenses for hypertension, diabetes, and cardiovascular and cerebrovascular diseases alone accounted for $12.5 \%$ of the total national health expenditure, among which selfadministered drugs for hypertension and diabetes accounted for more than $50 \%$ of medical expenses [13]. Therefore, for chronic disease patients, drug costs account for the vast majority of their medical costs. The long-term, high medical expenses have plunged families into poverty.

The drug cost for NCDs accounts for a large proportion of all medical costs, and this situation is expected to continue for a long time. However, current studies on NCDs' medical expenses both at home and abroad still focus on the factors influencing NCDs' hospitalization expenses, forecasts of hospitalization expenses, or the composition of costs $[14,15]$. At the same time, there are few studies on outpatient expenses [16, 17]. Outpatient can reflect the overall scale, service quality and medical-technology level of the hospital. They are the first step in developing diagnoses and treatments and are also an effective opportunity for the hospital to conduct external business [18, 19]. According to national statistics, drug costs in Zhejiang, Chongqing, and Jiangsu, among others, accounted for 51.75 to $74.37 \%$ of total outpatient expenses, and drug costs in all cities exceeded $50 \%$ of outpatient expenses in recent years in China [20-22].

The ZMDP started in primary medical and health institutions, moved to secondary hospitals, and then to all county-level hospitals across the country [23]. The tertiary hospital is the final implementer of ZMDP, patients with chronic diseases are the greatest beneficiaries of the ZMDP. As an essential strategic fulcrum for the western Chinese region, Chongqing lacks relevant research. Therefore, it is indispensable to analyze the effect of NCDs' outpatient drug cost after the ZMDP in Chongqing's tertiary hospital. Given that the patient's condition, such as gender, age, etc., is considered, this study intends to evaluate the impact of ZMDP on the average drug cost of multiple chronic disease outpatients based on interrupted time series analysis. Specifically, collect the drug cost of the three most common chronic diseases (diabetes, hypertension, and CHD) in the outpatient of a tertiary hospital in Chongqing. Five models were constructed to analyze the outpatient volume changes, total 
average drug costs, average drug costs by sex, average drug costs by age, and average drug costs by medical insurance type for the three diseases after the policy. Finally, it analyzes and compares the differences and puts forward targeted suggestions, aiming to reference decision-makers from the relevant industries and departments to refer to as they continue to deepen the medical and health system's reform. The flowchart is shown in Fig. 1.

\section{Methods}

\section{Setting and study population}

Chongqing is a megacity with a population of more than 30 million. It is also the only municipality directly under the Central Government's governance in the Midwest and is one of China's major central cities. This study explores the impact of the ZMDP on the average drug cost for NCDs outpatients in tertiary hospitals in Chongqing. To avoid the impact of comorbid diseases on drug cost, all diagnoses containing comorbidities were excluded from this study. The top 3 chronic diseases among outpatients were selected for the research focus, namely, diabetes (ICD-10 coded as E10-E14), hypertension (ICD-10 coded as I10), and coronary atherosclerotic heart disease (abbreviated as coronary heart disease, ICD-10 coded as I25).

\section{Outcome variables and data sources}

The outcome measure is defined as the average drug $\operatorname{cost} 1^{1}$ per month for NCDs' outpatients analyzed overall. The data are stratified according to gender, age and type of basic medical insurance, too. The data come

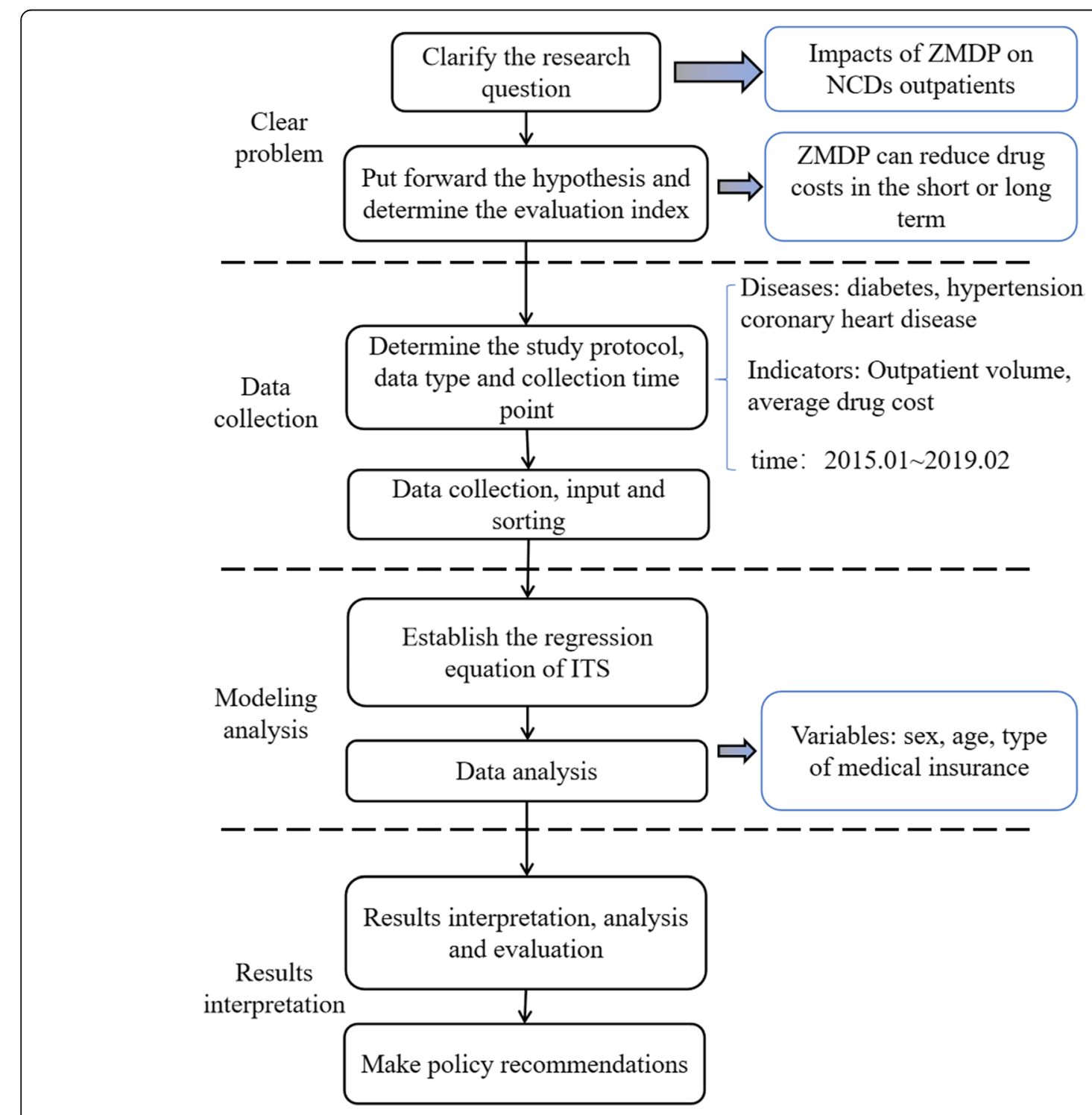

Fig. 1 The flowchart of ITS analysis of drug costs on NCDs outpatients 
from the hospital information system. From January 2015 to February 2019, 50 monthly observations were collected, sufficient for interrupted time series analysis. This study used the period when the ZMDP was first implemented in Chongqing's tertiary hospital in September 2017 as the intervention point. Interrupted time series analysis is used to estimate both the immediate (change in outcome levels) and long-term (change in outcome trends) effects of the policy.

\section{Statistical analysis}

Interrupted time series (ITS) analysis is a quasiexperimental research design proposed by Box and Tiao in 1975 to evaluate the effects of certain interventions retrospectively [24]. Its purpose is to determine whether the changes observed in the outcomes can be explained by long-term trends or are attributable to the intervention measures themselves. This is done by evaluating changes in the outcomes' levels and trends before and after the intervention measures [25]. The segmented regression time series model is one of the most commonly used ITS methods. It constructs multiple regression equations to perform regression analyses on the periods before and after the intervention measures, which requires fewer periods and relatively simple model building [26-28]. The segmented regression model based on the intervention period being in September 2017 is as follows:

$$
\begin{aligned}
Y_{t}= & \beta_{0}+\beta_{1} \times X_{\text {time }}+\beta_{2} \times X_{Z M D P}+\beta_{3} \times X_{\text {posttime }} \\
& +e_{t}
\end{aligned}
$$

Where $Y_{t}$ is the outcome variable for the study at time t; $X_{\text {time }}$ is the continuous-time variable, which represents the unit of time (such as months, years, etc.) used in the study, $X_{\text {time }}=1,2,3 \ldots n$. This study uses months as the unit, and the values of the observations are from 1 to 50; $X_{Z M D P}$ is a binary dummy variable, where the months before the intervention are represented by 0 (i.e., $X_{Z M D P}=0$ ), and those after are represented by 1 (i.e., $\left.X_{Z M D P}=1\right)$, with the change taking effect in the 33rd month of the series; $X_{\text {posttime }}$ is used in the time series analysis to count the months after the intervention. Months before the intervention are represented by 0 (i.e., $X_{\text {posttime }}=0$ ), and the months after the intervention are $X_{\text {posttime }}=1,2,3 \ldots n$, which ranges from 1 to 18 in this study.

$\beta_{0}$ represents a constant, and $\mathrm{t}=0$ reflects the baseline level; $\beta_{1}$ represents the estimated time trend before the intervention, that is, the slope of $X_{\text {time }}$ before the intervention; $\beta_{2}$ represents the instantaneous level change

\footnotetext{
${ }^{1}$ The exchange rate of the RMB against the US dollar in 2019: 100 US dollars $=689.85$ yuan. The data comes from the National Bureau of Statistics of China (https://data.stats.gov.cn).
}

due to the intervention; and $\beta_{3}$ reflects the time trend change after the intervention is implemented, that is, the amount by which the slope changes. $e_{t}$ is the random error value. The data analysis was performed using the Statistical Analysis System, version 9.4 (SAS, North Carolina State University, USA). The level of significance was set $P<0.05$.

\section{Results}

From January 2015 to February 2019, the outpatient volume for the top three chronic diseases in a tertiary hospital in Chongqing was 350,848, including 197,227 diabetes, 130,993 hypertension and 22,628 CHD. Separately, among all 197,227 diabetic outpatients, 96,072 were women and 101,155 were men. There were 101, 838 diabetes aged $46-65$ years, accounting for $51.63 \%$ of the total. The majority of medical payments are through BMIUE (182,432 person-visits in total). Second, among all 130,993 hypertension outpatients, 69,600 were women and 61,393 were men. Patients were mainly 46 years old or older. The cumulative BMIUE patients were 122,273 , and the BMIRC patients were the lowest, only 232. Finally, among all 22,628 CHD outpatients, 8836 were women and 13,792 were men. More than half of the patients were over 65 years old, with 12,676 patients. Like diabetes and hypertension, most patients use BMIUE for payment, accounting for $89.87 \%$ of the total.

The total average drug cost of outpatients for treating chronic diseases was 688.65 yuan. Diabetes, hypertension and CHD were 736.56 yuan, 601.00 yuan and 778.36 yuan, respectively. Among diabetic outpatients, the average drug cost was 736.56 yuan, 720.06 yuan for males, and 753.94 yuan for females. Among hypertension outpatients, the average drug cost was 601.00 yuan, 607.45 yuan for males, and 595.31 yuan for females. Among CHD outpatients, the average drug cost was 778.36 yuan, 805.85 yuan for males, and 735.46 yuan for females. Diabetic, hypertension and CHD all have the highest average drug costs for those over 65 years old, which are 822.62 yuan, 690.01 yuan and 796.56 yuan respectively. Similarly, the average drug costs of BMIRC are the highest for the three diseases, which are 1029.62 yuan, 675.23 yuan and 977.25 yuan respectively. As shown in Table 1, the three diseases' outpatient volume and average drug costs are quite different. Therefore, this study analyzes the three diseases separately better to compare the impact of the implementation of the ZMDP.

\section{Model 1: outpatient volume as the dependent variable}

The ITS results show that the average monthly outpatient visits for diabetes, hypertension, and CHD were $3692.00,3211.00$ and 413.38 at baseline, all of which were statistically significant $(P<0.001)$. The $\beta 1$ of the 
Table 1 Outpatient volume and the average drug cost for three chronic diseases from January 2015 to February 2019

\begin{tabular}{|c|c|c|c|c|c|c|c|c|c|}
\hline \multirow[t]{2}{*}{ Indicator } & & \multicolumn{4}{|c|}{ Outpatient volume (person-month) } & \multicolumn{4}{|c|}{ Average drug cost (RMB) } \\
\hline & & Total & Diabetes & Hypertension & $\begin{array}{l}\text { Coronary heart } \\
\text { disease }\end{array}$ & Total & Diabetes & Hypertension & $\begin{array}{l}\text { Coronary heart } \\
\text { disease }\end{array}$ \\
\hline \multirow[t]{2}{*}{ Sex } & Female & $\begin{array}{l}174 \\
508\end{array}$ & 96,072 & 69,600 & 8836 & 689.74 & 753.94 & 595.31 & 735.46 \\
\hline & Male & $\begin{array}{l}176 \\
340\end{array}$ & 101,155 & 61,393 & 13,792 & 687.56 & 720.06 & 607.45 & 805.85 \\
\hline \multirow[t]{3}{*}{ Age } & $<46$ & 25,024 & 15,380 & 9040 & 604 & 468.51 & 535.50 & 346.92 & 582.68 \\
\hline & $46-65$ & $\begin{array}{l}169 \\
601\end{array}$ & 101,838 & 58,415 & 9348 & 649.35 & 699.32 & 543.50 & 766.34 \\
\hline & $>65$ & $\begin{array}{l}156 \\
223\end{array}$ & 80,009 & 63,538 & 12,676 & 766.57 & 822.62 & 690.01 & 796.56 \\
\hline \multirow[t]{4}{*}{$\begin{array}{l}\text { Basic medical insurance } \\
\text { type }\end{array}$} & BMIUE & $\begin{array}{l}325 \\
040\end{array}$ & 182,432 & 122,273 & 20,335 & 712.42 & 763.34 & 621.26 & 803.72 \\
\hline & BMIUR & 12,790 & 8548 & 3245 & 997 & 376.81 & 390.80 & 291.68 & 533.91 \\
\hline & BMIRC & 806 & 417 & 232 & 157 & 917.41 & 1029.62 & 675.23 & 977.25 \\
\hline & Self-insured & 12,212 & 5830 & 5243 & 1139 & 367.44 & 384.82 & 316.65 & 512.26 \\
\hline \multirow[t]{5}{*}{ Year } & 2015 & 89,795 & 46,237 & 38,335 & 5223 & 704.56 & 772.03 & 609.88 & 802.17 \\
\hline & 2016 & 89,077 & 46,607 & 36,598 & 5872 & 711.89 & 775.03 & 619.63 & 785.73 \\
\hline & 2017 & 91,310 & 49,679 & 35,675 & 5956 & 684.35 & 731.93 & 597.58 & 807.23 \\
\hline & 2018 & 71,809 & 47,951 & 18,927 & 4931 & 656.25 & 684.80 & 564.39 & 731.30 \\
\hline & $\begin{array}{l}2019 \text { (Jan- } \\
\text { Feb) }\end{array}$ & 8857 & 6753 & 1458 & 646 & 600.43 & 629.96 & 458.56 & 611.99 \\
\hline \multirow[t]{2}{*}{ ZMDP implemented } & NO & $\begin{array}{l}242 \\
006\end{array}$ & 126,979 & 99,728 & 15,299 & 707.74 & 769.24 & 614.99 & 801.88 \\
\hline & YES & $\begin{array}{l}108 \\
842\end{array}$ & 70,248 & 31,265 & 7329 & 646.20 & 677.50 & 556.38 & 729.28 \\
\hline Total & & $\begin{array}{l}350 \\
848\end{array}$ & 197,227 & 130,993 & 22,628 & 688.65 & 736.56 & 601.00 & 778.36 \\
\hline
\end{tabular}

Abbreviations: BMIUE basic medical insurance for urban employees, BMIUR basic medical insurance for urban residents, $B M I R C$ basic medical insurance for retired cadres

three diseases was $13.63(P>0.05),-6.05(P>0.05)$ and $3.45(P=0.001)$, shows no significant difference in the outpatient volume changes of diabetes and hypertension before ZDMP. The change of CHD outpatients' volume was statistically significant, with an average increase of 3.45 per month. There was no significant difference in the outpatient volume after the policy in instantaneous changes (all $P>0.05$ ). The three diseases' outpatient volume has shown a downward trend after the policy. $\beta 3$ of $-53.04(P=0.012),-142.19(P<0.001)$ and -12.16 $(P<0.001)$ were statistically significant. It shows that compared with before the policy, the monthly outpatient visits for diabetes, hypertension and CHD have dropped by about 53, 142, and 12, respectively (Table 2, Fig. 2). In general, after implementing ZDMP, the outpatient volume for the three diseases has shown a downward

Table 2 The parameters of the interrupted time series analysis for NCDs outpatients (outpatient volume and average drug cost as the dependent variables respectively)

\begin{tabular}{|c|c|c|c|c|c|c|c|c|c|}
\hline \multirow[t]{2}{*}{ Indicator } & & \multicolumn{2}{|c|}{$\beta 0$} & \multicolumn{2}{|c|}{$\beta 1$} & \multicolumn{2}{|c|}{$\beta 2$} & \multicolumn{2}{|c|}{$\beta 3$} \\
\hline & & $\begin{array}{l}\text { Estimated } \\
\text { value }\end{array}$ & $\begin{array}{l}P \text { - } \\
\text { value }\end{array}$ & $\begin{array}{l}\text { Estimated } \\
\text { value }\end{array}$ & $\begin{array}{l}P \text { - } \\
\text { value }\end{array}$ & $\begin{array}{l}\text { Estimated } \\
\text { value }\end{array}$ & $\begin{array}{l}P \text { - } \\
\text { value }\end{array}$ & $\begin{array}{l}\text { Estimated } \\
\text { value }\end{array}$ & $\begin{array}{l}P- \\
\text { value }\end{array}$ \\
\hline \multirow{3}{*}{$\begin{array}{l}\text { Outpatient volume } \\
\text { (person-month) }\end{array}$} & Diabetes & 3692.00 & $<0.001$ & 13.63 & 0.056 & 226.24 & 0.302 & -53.04 & 0.012 \\
\hline & Hypertension & 3211.00 & $<0.001$ & -6.05 & 0.084 & 151.17 & 0.081 & -142.19 & $<0.001$ \\
\hline & $\begin{array}{l}\text { Coronary heart } \\
\text { disease }\end{array}$ & 413.38 & $<0.001$ & 3.45 & 0.001 & -22.92 & 0.302 & -12.16 & $<0.001$ \\
\hline \multirow{3}{*}{$\begin{array}{l}\text { Average drug cost } \\
\text { per month (RMB) }\end{array}$} & Diabetes & 761.80 & $<0.001$ & 0.16 & 0.835 & -45.51 & 0.029 & -4.44 & 0.029 \\
\hline & Hypertension & 605.09 & $<0.001$ & 0.53 & 0.315 & -19.79 & 0.276 & -5.87 & $<0.001$ \\
\hline & $\begin{array}{l}\text { Coronary heart } \\
\text { disease }\end{array}$ & 780.21 & $<0.001$ & 2.26 & 0.257 & -77.46 & 0.047 & -10.23 & 0.036 \\
\hline
\end{tabular}


trend to varying degrees. It has the most significant impact on hypertension, followed by diabetes, and finally CHD.

\section{Model 2: average drug cost as the dependent variable} During the study period, the average drug costs for diabetes, hypertension, and CHD were 761.80, 605.09 and 780.21 yuan at baseline, all of which were statistically significant $(P<0.001)$. In terms of instantaneous changes, the $\beta 2$ of these three are $-45.51,-19.79$ and -77.46 . It shows that after this policy, the average drug costs of diabetes and CHD have decreased by 45.51 yuan and 77.46 yuan, respectively, which is statistically significant (P 0.029 and 0.047 , respectively). Simultaneously, there was no significant difference in transient changes in hypertension $(P>0.05)$. The average drug costs for diabetes, hypertension, and CHD have all shown a downward trend after the policy. $\beta 3$ was $-4.44,-5.87$ and -10.23 , all of which were statistically significant (all $P<0.05$ ). It shows that compared with before the policy, the average monthly drug costs of the three have dropped by about 4.44 yuan, 5.87 yuan, and 10.23 yuan, respectively (Table 2, Fig. 3). After implementing ZDMP, the three diseases' average drug costs have shown instantaneous changes and (or) downward trends to varying degrees. In terms of transient and trend changes $(\beta 1+\beta 3)$, it has the most significant impact on the average drug cost of CHD, followed by diabetes, and finally hypertension.

\section{Model 2.1: average drug cost by sex as the dependent variable}

By gender comparison, the baseline average monthly drug costs of male and female patients with different diseases are statistically significant (all $P<0.001$ ). Before ZDMP, there was no significant difference in all patients' average drug costs (all $P>0.05$ ). In terms of instantaneous changes, $\beta 2$ in male diabetes, male hypertension and female diabetes were - 51.21 $(P=0.017),-48.26$ $(P=0.047)$ and $-41.24(P=0.011)$. After the policy, only the instantaneous changes in the above three categories' average drug costs were statistically significant, with a decrease of 51.21 yuan, 48.26 yuan and 41.24 yuan, respectively. There was no significant difference in the instantaneous changes in men's average drug costs with CHD, women with hypertension, and CHD $(P>0.05)$. From the perspective of trend changes, after the policy, the decline in average drug costs for male diabetic patients is not significant $(\beta 3=-3.62, P>0.05)$. The downward trend of the remaining patients' average drug cost was statistically significant (all $P<0.05$ ). Specifically, male hypertension and male CHD's long-term trend changes decreased by 7.78 yuan and 11.58 yuan per month, respectively. The long-term trends of female diabetes, hypertension, and CHD decreased by 4.78 yuan, 4.40 yuan, and 12.51 yuan (Table 3, Fig. 4).

\section{Model 2.2: average drug cost by age as the dependent variable}

A comparison of ages shows that the baseline average monthly drug costs of patients of different age groups were statistically significant (all $P<0.001$ ). Before ZDMP, only the average drug cost of patients with diabetes under 46 years old had a statistically significant change ( $\beta 1$ was $1.11, P=0.005$ ). It shows that before the policy, the average monthly drug costs for diabetic patients < 46 years old increased by 1.11 yuan. However, there was no significant difference in the remaining patients' average drug cost (all $P>0.05$ ). In terms of instantaneous changes, $\beta 2$ for diabetes with $46-65$ and CHD with $>65$ are $-54.4(P<0.001)$ and $-102.61(P=$ 0.030 ), respectively. It shows that after the policy, these two patients' average drug costs have instantaneously decreased by 54.4 yuan and 102.61 yuan. The transient changes of the remaining patients were not statistically significant (all $P>0.05$ ). In terms of trend changes, the average drug costs of 46-65 years old for the three diseases have a statistically significant decline $(P<0.05)$. Specifically, the long-term trends of patients with diabetes, hypertension, and CHD decreased by 3.16 yuan, 4.54 yuan, and 11.70 yuan per month, respectively. Only the average drug cost for hypertension in the age groups of $<46$ and $>65$ has a significant downward trend, with
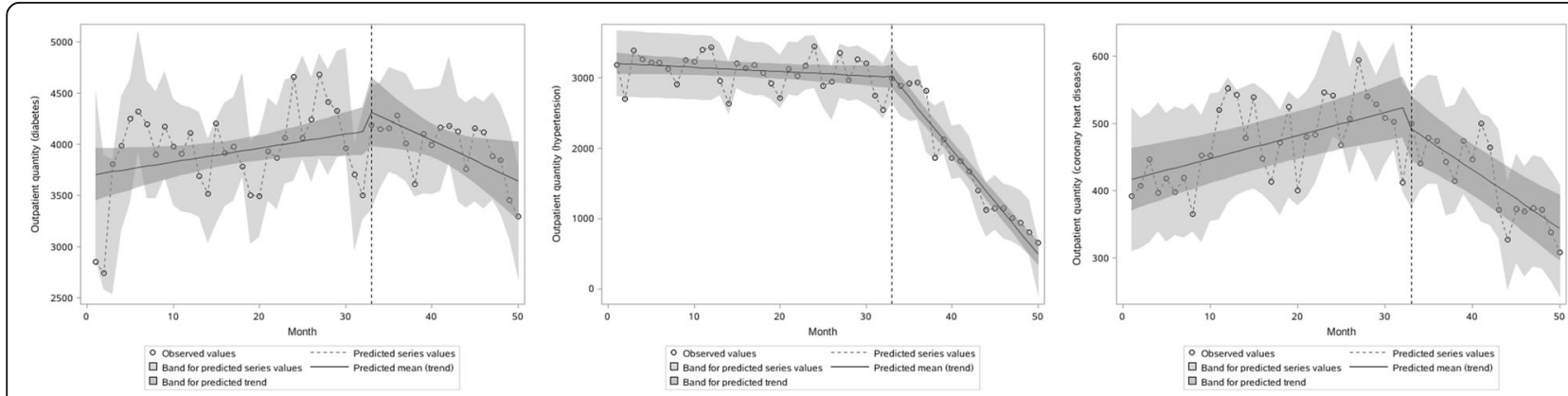

Fig. 2 Estimated changes in outpatient volume for patients with diabetes (a), hypertension (b), and coronary heart disease (c) 

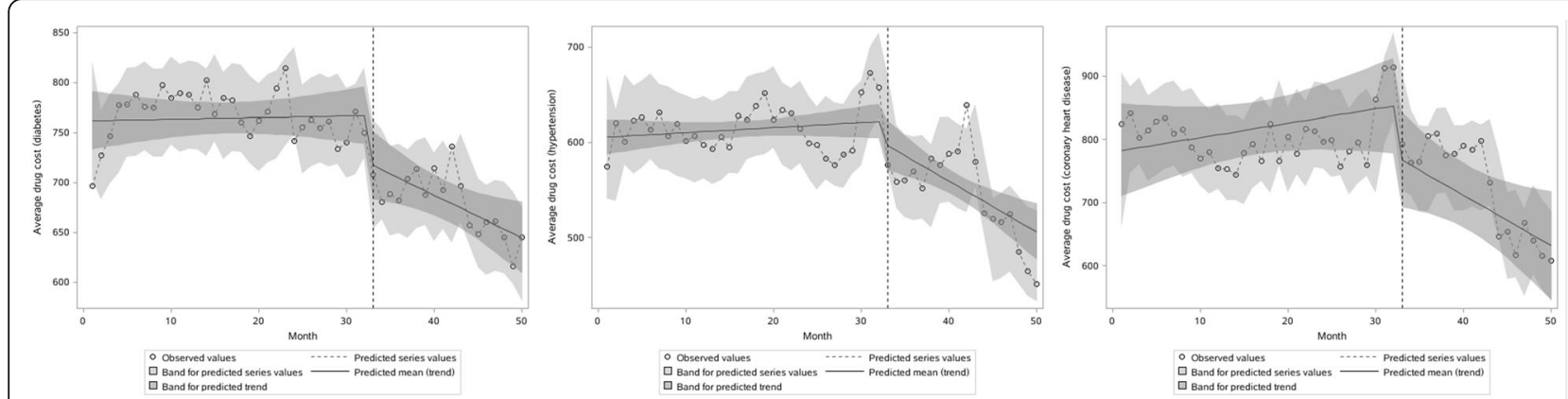

Fig. 3 Estimated changes in average drug costs for patients with diabetes (a), hypertension (b), and coronary heart disease (c)

a monthly decrease of 3.66 yuan and 8.32 yuan, respectively (Table 3, Fig. 5).

\section{Model 2.3: average drug cost by basic medical insurance type as the dependent variable}

The main payment methods for outpatients are BMIUE and BMIUR. The comparison found that the baseline average monthly drug costs with different medical insurance payment methods were statistically significant $(P<$ 0.001). Before the ZDMP, only the average drug cost of BMIUR 's diabetes had a statistically significant change $(\beta 1=1.10, P=0.006)$. It shows that before the policy, the average monthly drug cost of BMIUR's diabetes increased by 1.10 yuan. There was no significant difference

Table 3 The parameters of the interrupted time series analysis for NCDs outpatients of different sexes, ages and basic medical insurance (average drug cost as the dependent variable)

\begin{tabular}{|c|c|c|c|c|c|c|c|c|c|}
\hline \multirow[t]{2}{*}{ Indicator } & & \multicolumn{2}{|l|}{$\beta 0$} & \multicolumn{2}{|l|}{$\beta 1$} & \multicolumn{2}{|l|}{$\beta 2$} & \multicolumn{2}{|l|}{$\beta 3$} \\
\hline & & Estimated value & $P$-value & Estimated value & $P$-value & Estimated value & $P$-value & Estimated value & $P$-value \\
\hline \multicolumn{10}{|l|}{$\overline{S e x}$} \\
\hline \multirow[t]{3}{*}{ Male } & Diabetes & 740.74 & $<0.001$ & 0.33 & 0.679 & -51.21 & 0.017 & -3.62 & 0.078 \\
\hline & Hypertension & 600.16 & $<0.001$ & 1.54 & 0.097 & -48.26 & 0.047 & -7.78 & 0.001 \\
\hline & Coronary heart disease & 833.00 & $<0.001$ & 0.47 & 0.712 & -9.12 & 0.797 & -11.58 & 0.001 \\
\hline \multirow[t]{3}{*}{ Female } & Diabetes & 791.45 & $<0.001$ & -0.30 & 0.547 & -41.24 & 0.011 & -4.78 & 0.001 \\
\hline & Hypertension & 610.14 & $<0.001$ & -0.24 & 0.599 & -2.97 & 0.855 & -4.40 & 0.002 \\
\hline & Coronary heart disease & 729.16 & $<0.001$ & 1.43 & 0.191 & 27.96 & 0.412 & -12.51 & $<0.001$ \\
\hline \multicolumn{10}{|l|}{ Age } \\
\hline \multirow[t]{3}{*}{$0-45$} & Diabetes & 507.08 & $<0.001$ & 1.11 & 0.005 & -13.96 & 0.246 & 1.85 & 0.064 \\
\hline & Hypertension & 353.70 & $<0.001$ & -0.21 & 0.734 & 22.70 & 0.255 & -3.66 & 0.030 \\
\hline & Coronary heart disease & 541.37 & $<0.001$ & 3.01 & 0.210 & -28.93 & 0.729 & -9.22 & 0.163 \\
\hline \multirow[t]{3}{*}{$46-65$} & Diabetes & 720.53 & $<0.001$ & 0.33 & 0.336 & -54.40 & $<0.001$ & -3.16 & 0.001 \\
\hline & Hypertension & 555.77 & $<0.001$ & 0.06 & 0.883 & -20.16 & 0.158 & -4.54 & $<0.001$ \\
\hline & Coronary heart disease & 781.70 & $<0.001$ & 0.76 & 0.544 & 7.06 & 0.849 & -11.70 & $<0.001$ \\
\hline \multirow[t]{3}{*}{$>65$} & Diabetes & 874.52 & $<0.001$ & -0.52 & 0.709 & -55.50 & 0.094 & -6.15 & 0.088 \\
\hline & Hypertension & 689.67 & $<0.001$ & 1.16 & 0.306 & -43.06 & 0.129 & -8.32 & 0.005 \\
\hline & Coronary heart disease & 802.53 & $<0.001$ & 2.28 & 0.331 & -102.61 & 0.030 & -8.91 & 0.117 \\
\hline \multicolumn{10}{|c|}{ Basic medical insurance } \\
\hline \multirow[t]{3}{*}{ BMIUE } & Diabetes & 800.24 & $<0.001$ & -0.19 & 0.822 & -53.37 & 0.017 & -4.24 & 0.054 \\
\hline & Hypertension & 623.11 & $<0.001$ & 1.02 & 0.170 & -59.63 & 0.010 & -5.60 & 0.021 \\
\hline & Coronary heart disease & 818.94 & $<0.001$ & 1.49 & 0.338 & -63.06 & 0.117 & -10.02 & 0.010 \\
\hline \multirow[t]{3}{*}{ BMIUR } & Diabetes & 381.93 & $<0.001$ & 1.10 & 0.006 & -49.01 & 0.001 & 0.01 & 0.993 \\
\hline & Hypertension & 281.34 & $<0.001$ & 0.69 & 0.349 & 10.71 & 0.682 & -3.53 & 0.108 \\
\hline & Coronary heart disease & 573.32 & $<0.001$ & -0.54 & 0.808 & -42.62 & 0.539 & -1.27 & 0.822 \\
\hline
\end{tabular}



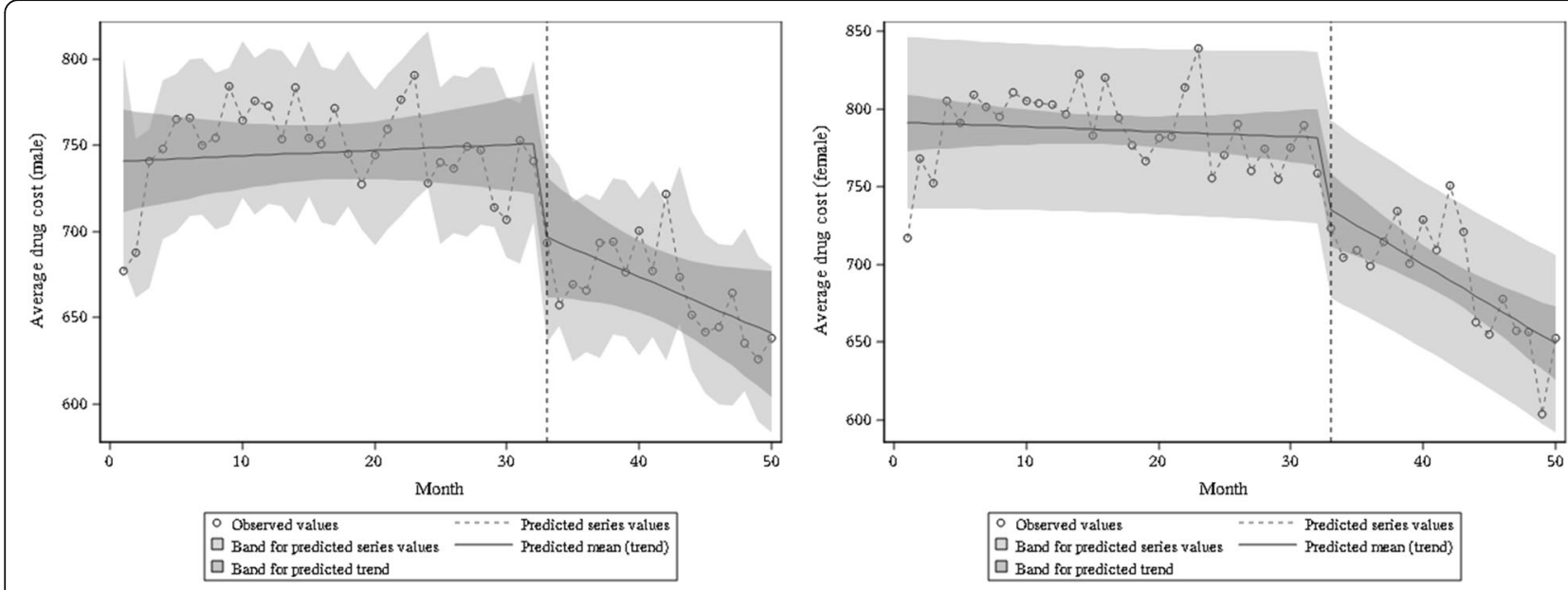

a
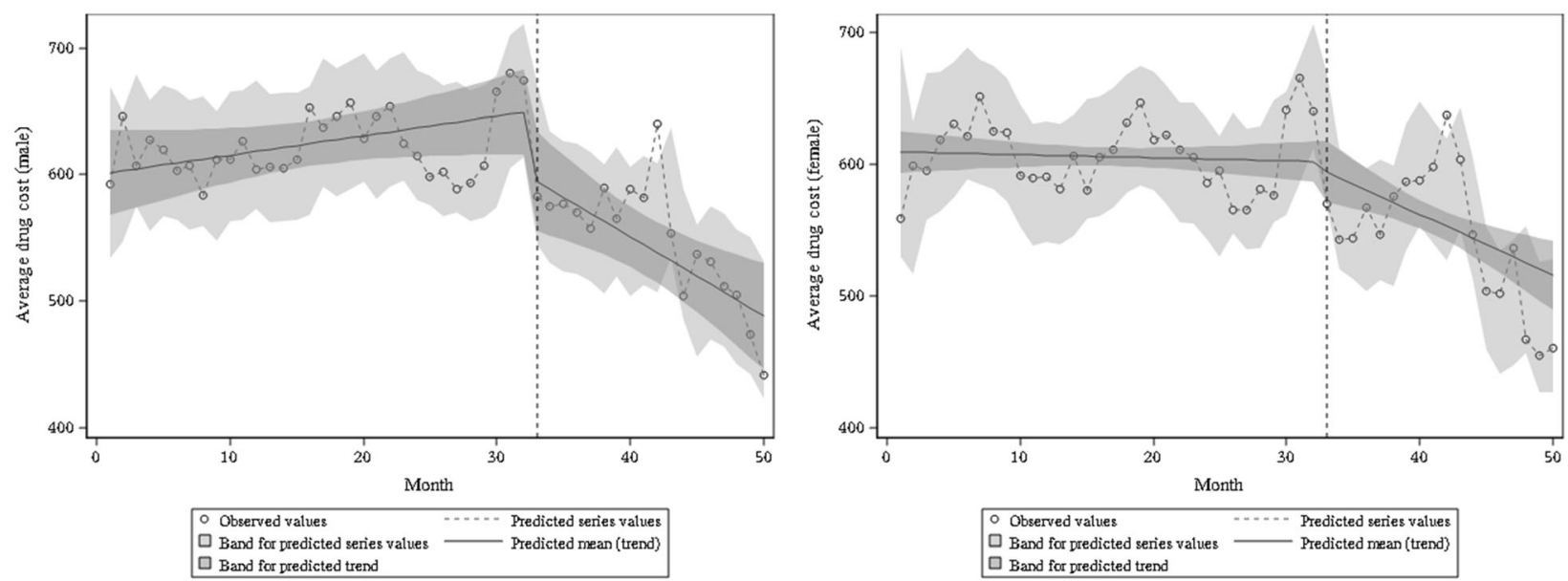

b
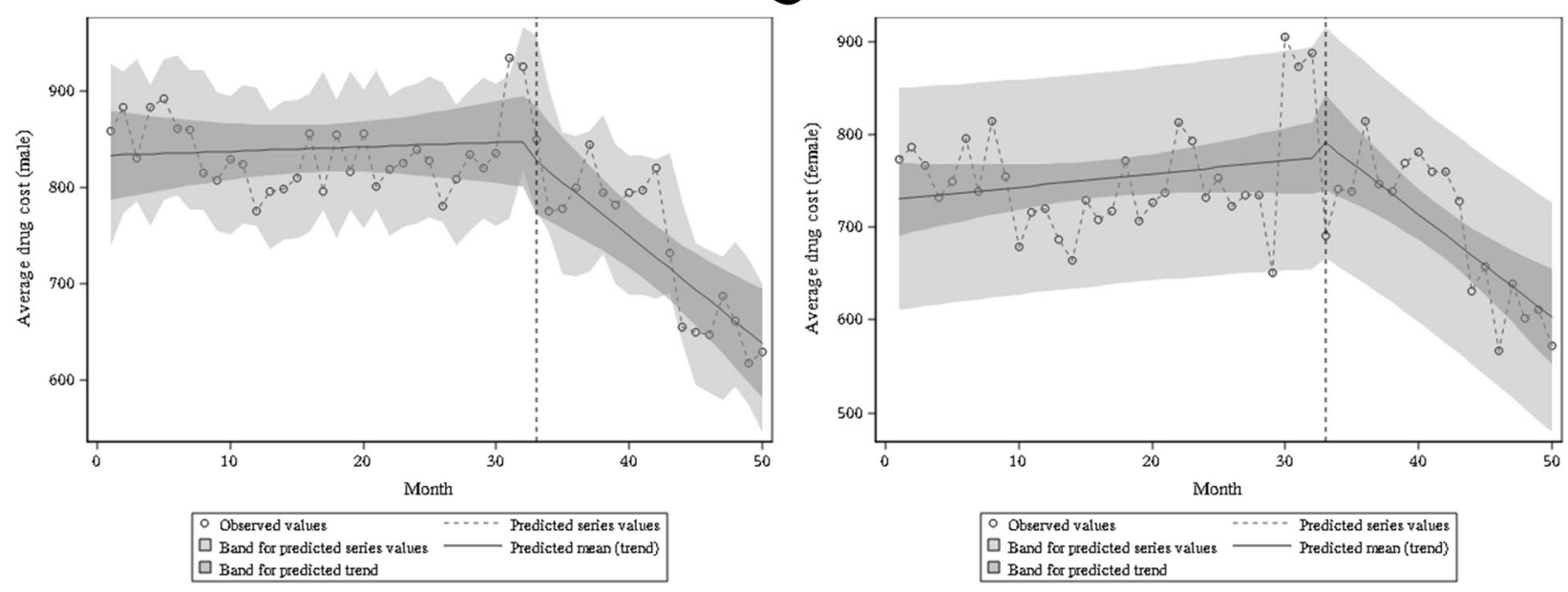

c

Fig. 4 Estimated changes in average drug costs for patients of different sexes with diabetes (a), hypertension (b), and coronary heart disease (c). On the left is male and on the right is female 
in the remaining patients' average drug cost (all $P>$ 0.05). In terms of transient changes, BMIUE's diabetes, BMIUE's hypertension, and BMIUR's diabetes $\beta 2$ were $-53.37(P=0.017),-59.63(P=0.010)$ and $49.01(P=0.001)$, respectively. It shows that after the policy, the average drug costs of these three types of patients have instantaneously decreased by 53.37 yuan, 59.63 yuan and 49.01 yuan, respectively. The instantaneous changes in the remaining patients' average drug costs were not statistically significant (all $P>0.05$ ). From the perspective of trend changes, the average drug costs of BMIUE's hypertension and BMIUE's diabetes have a statistically significant decline ( $P$-value were 0.021 and 0.010 , respectively), with a monthly decrease of 5.60 yuan and 10.02 yuan, respectively (Table 3, Fig. 6).

\section{Discussion}

This study analyzes the changes in average drug costs per month for NCDs' outpatients for 2 years after the full implementation of the ZMDP in the tertiary hospital in Chongqing. We find that after the ZMDP, the average drug costs of the three most common NCDs' outpatients (diabetes, hypertension and coronary heart disease) all have a significant downward trend, with a monthly decrease of 4.44 yuan, 5.87 yuan and 10.23 yuan respectively (all $P<0.05$ ). Zhang [29] finds that the ZMDP can reduce the prescription drug cost for hypertension in secondary hospitals by an average of 2.01 yuan, which illustrates this policy's broad applicability. Contrary to our research, Yan found that tertiary hospitals' average outpatient drug expenditure showed a slow downward trend before the intervention and an upward trend after the
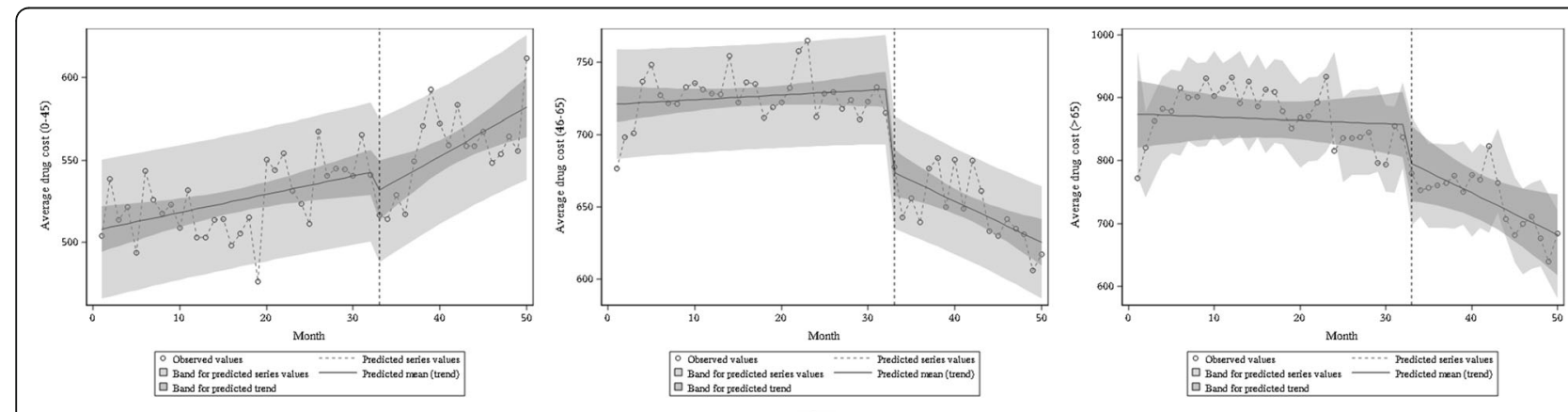

a
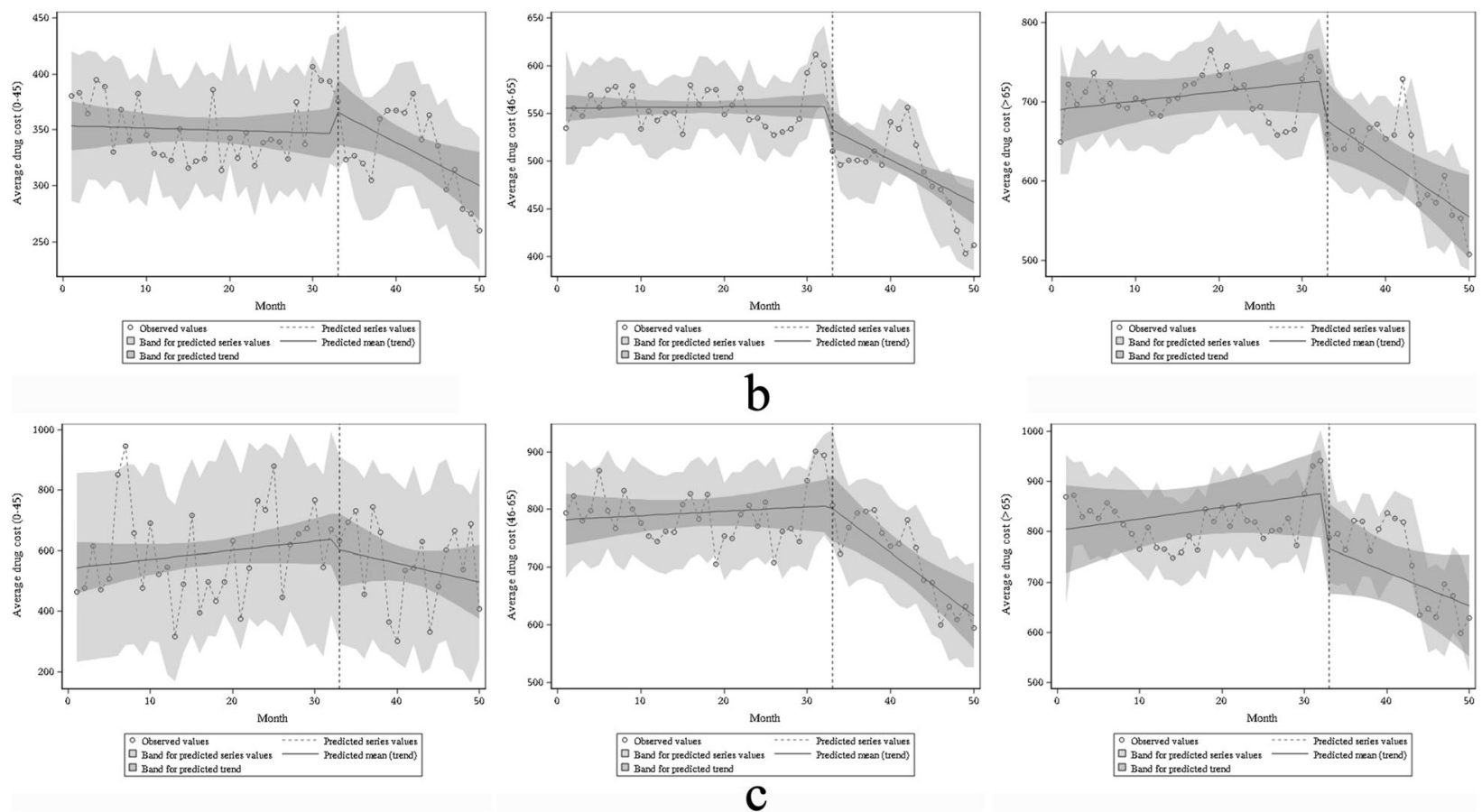

Fig. 5 Estimated changes in average drug costs for patients of different ages with diabetes (a), hypertension (b), and coronary heart disease (c). On the left is the under-45 group, in the middle is the 45-65 group, and on the right is the over-65 group 

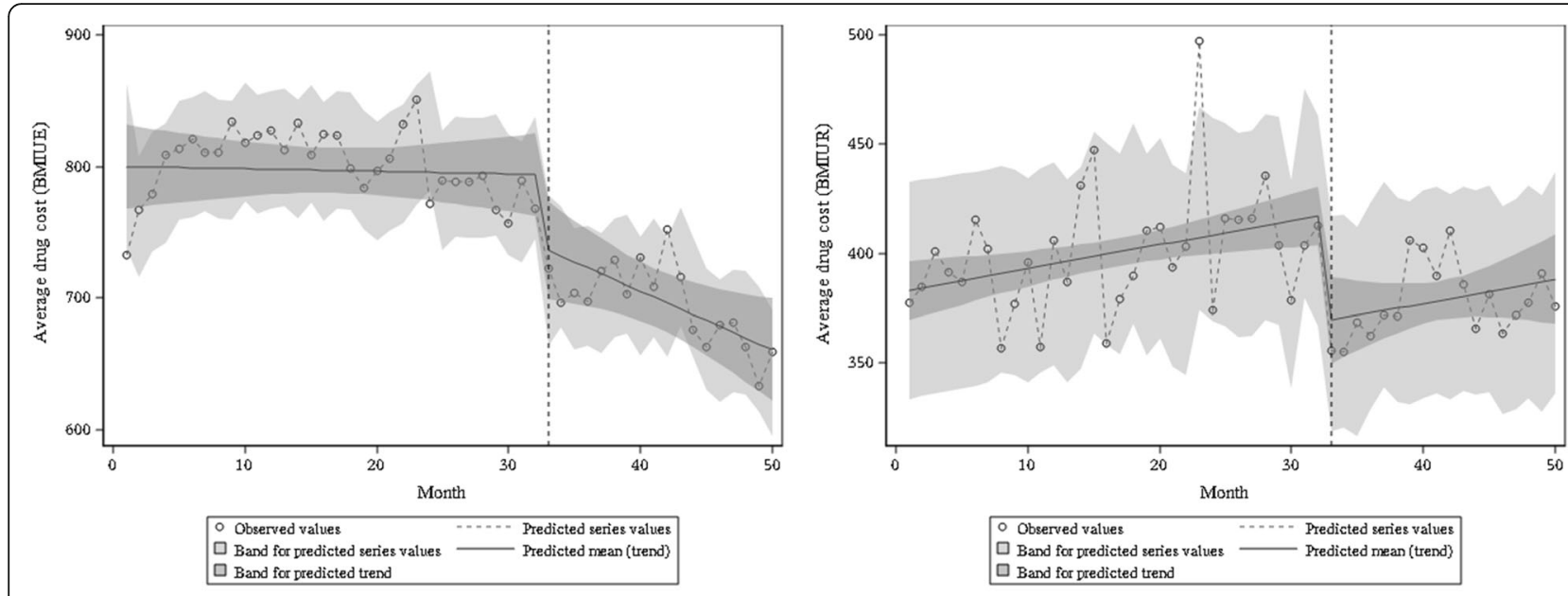

a
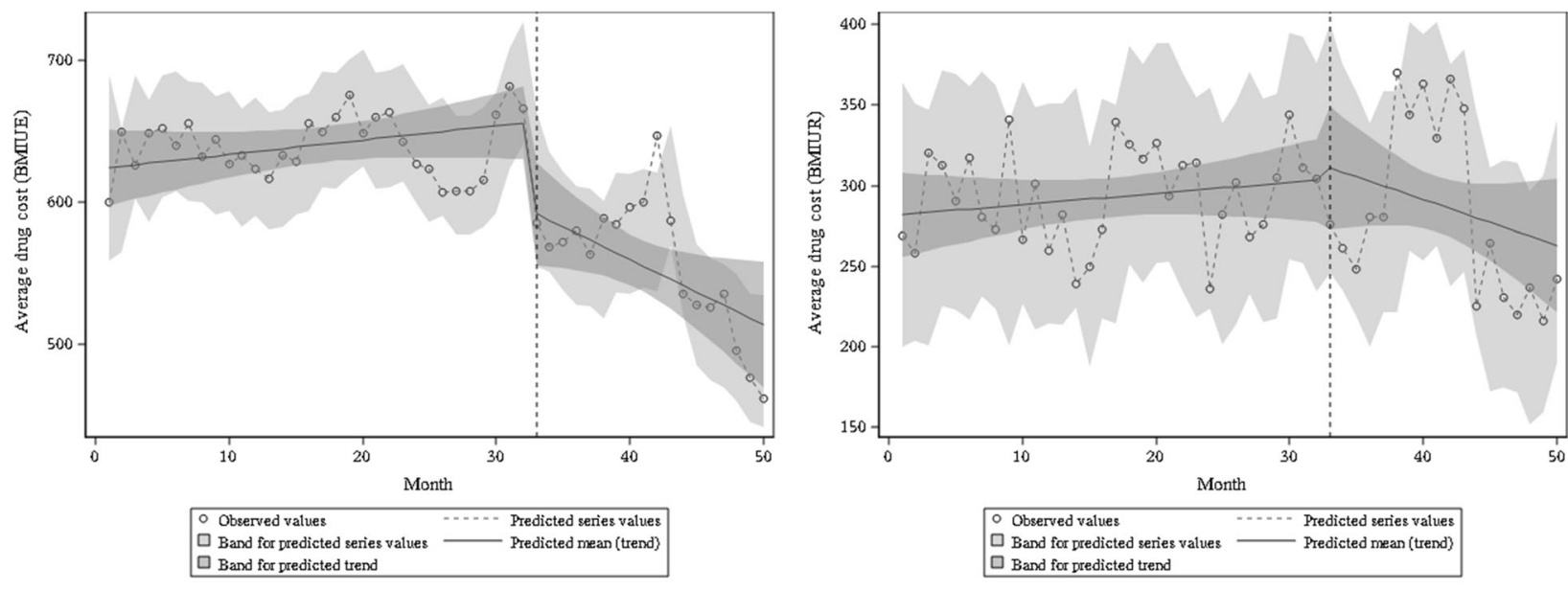

b
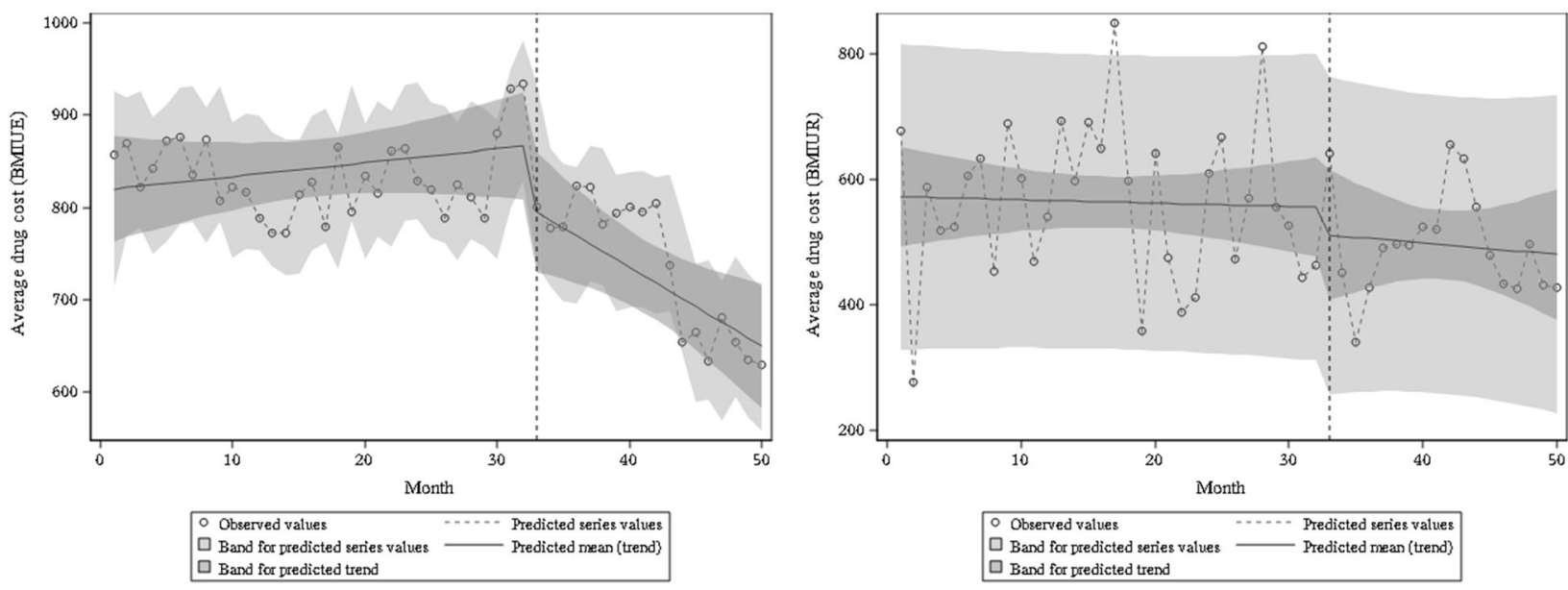

C

(trend)

$\square$ Band for gredicted trend

Fig. 6 Estimated changes in average drug costs for diabetic patients (a), hypertensive patients (b), and coronary heart disease patients (c) under different basic medical insurance plans. On the left is BMIUE, on the right is BMIUR 
intervention [8]. It might because Yan's research scope is too broad, and the adaptability of policies between different diseases is not considered.

We also find that different diseases have different sensitivity to the policy. The instantaneous changes in diabetes and CHD are statistically significant, and the analysis decreased by 45.51 yuan and 77.46 yuan, while there is no significant difference in CHD. This illustrates that, on the whole, the ZMDP effectively regulates the drug cost for different diseases, has universal applicability, consistent with the study's findings by Wang [30]. Chao's [31] research also shows that reasonable prices for essential drugs and the implementation of the ZMDP can reduce the average cost of prescriptions. But the ZMDP also puts financial pressure on hospitals. Hospitals respond to the economic impact of a sharp drop in prescription drug revenue by increasing revenue from other treatments and procedures, such as imaging tests [7]. Therefore, the evaluation of medical reform's effect must consider the sensitivity of different diseases to policies. Simultaneously, the synergy of other indicators should also be considered comprehensively, such as total medical costs, inspection costs, and so on.

Simultaneously, the outpatient visits also experienced a downward trend. The monthly outpatient visits for diabetes, hypertension and CHD have dropped by about 53, 142, and 12, respectively, which may be synergistic with ZMDP and the hierarchical medical system [32]. "Hierarchical medical system" refers to a system by which diseases are classified according to their severity and treatment difficulty. Medical institutions of different levels undertake different diseases and gradually ensure the medical process is carried out at all levels, from general medicine to specialized therapies [33]. Implementing the hierarchical medical system has enabled patients with chronic diseases to turn to primary medical and health service institutions or nearby pharmacies for related consultations, which has reduced the number of outpatient visits in tertiary hospitals. To some extent, ZMDP plays an active role in relieving medical insurance funds' pressure and promoting hierarchical diagnosis and treatment implementation.

The evaluation and analysis of the three diseases' drug costs found that they are all affected by the policy. Still, our further study found that the results under different indicators are different and the results may be affected by interference factors. This study shows that the longterm trend in the average drug cost for outpatients by sex has declined after the ZMDP, indicating that the policy has practical applicability. However, further analysis revealed that ZMDP has different effects on patients of different ages with various diseases. Only patients aged 46 to 65 showed a consistent decline in the long-term trend in drug costs after the ZMDP, indicating that this policy is more beneficial to $46-65$-year-old patients. This may be due to the relatively mild conditions of younger patients with treatments that require fewer drugs, so there is less change in drug costs. Our study finds that younger patients had the lowest baseline, which supports this statement, too. However, patients in the older age are often more likely to use fast-acting drugs that have higher prices due to their serious illnesses, and the demand for drugs among these patients is also greater. Therefore, the average drug cost per month has not been significantly reduced after the zero mark-up policy.

To control NCDs' drug costs, it is also necessary to control the NCDs' prevalence at the source and strengthen preventive investments in chronic diseases. This needs to start with primary prevention, spreading the concept of self-prevention to the public and raising awareness of chronic disease prevention among people of all ages. Among them, special attention should be paid to the compliance of elderly patients with chronic diseases, especially those with less education. Because they need to take many different drugs for a long time, a poor understanding of prescription usage and dosage may have serious consequences [34].

We find that the ZMDP has different adjustment strengths for different types of basic medical insurance. Overall, the long-term average drug cost for BMIUE patients after the ZMDP shows a continuous downward trend. For patients with BMIUR, the average drug cost for diabetic patients decreased by 49.01 yuan $(P=0.001)$. Still, there was no significant change in the average drug cost for patients with the other two diseases. In this study, the baseline level of the average drug cost for patients with BMIUE was higher than that for patients with BMIUR. This may be due to the different reimbursement ways of the two basic medical insurance plans. The BMIUR cannot reimburse outpatient expenses. However, the patients' outpatient expenses with BMIUE can be deducted from the personal account amount, including a partial return of the paid amount. Wang's [35] related research noted that basic medical insurance popularization had changed patients' ability to pay and reduced patients' sensitivity to drug costs. Besides, due to the limited reimbursement rate of patients in the BMIUR plan, such patients are more likely to choose to purchase drugs outside of the hospital independently, so the implementation of the ZMDP in tertiary hospitals has little effect on their costs. In contrast, patients enrolled in BMIUE may have a relatively higher awareness of rational drug use or are more willing to choose to purchase drugs at hospitals. Hence, the cancellation of the drug mark-up fee at public hospitals provides more significant benefits to patients enrolled in BMIUE [36]. Therefore, when the country evaluates the effects of health reforms and further reforms, it should 
analyze the overall situation and define specific indicators based on different medical insurance payment methods, other regions, and various medical institutions.

The contribution of this research to the literature is reflected in the following aspects. First, this research provides a useful reference on the impact of the ZMDP on the drug cost of NCDs' outpatients. Second, in this study, a series of covariate effects were controlled to eliminate potential confounding effects. Less control over confounding factors may overestimate or underestimate specific policies' impact. Finally, we hope this study could provide meaningful enlightenment for the subsequent deepening of the medical reform plan.

\section{Conclusions}

Currently, research on evaluating drug costs for NCDs' outpatients after the ZMDP lacks. This study takes Chongqing, a key city in western China, as an example and demonstrates the policy's applicability in the field of chronic diseases by studying the impact of the ZMDP in tertiary hospitals on outpatient visits and drug costs. This study finds that the ZMDP reform can significantly reduce the medicines expenditure and the outpatient visits for different chronic diseases outpatient and regulate and control other diseases. At the same time, this study uses the ITS method to build multiple models to analyze drug costs under various confounding factors, providing a specific reference for the formulation of a deepening health reform plan. However, this study only focuses on exploring the indicator of the average drug cost. Despite the large sample size, the sample's representativeness and the credibility of this study's conclusions need to be improved. Further research will be carried out by increasing the evaluation index and sample size to evaluate these strategies' long-term impact in a broader range.

\section{Abbreviations}

ZMDP: Zero mark-up drug policy; ITS: Interrupted time series;

NCDs: Noninfectious chronic diseases; CHD: Coronary heart disease; BMIUE: Basic medical insurance for urban employees; BMIUR: Basic medical insurance for urban residents; BMIRC: Basic medical insurance for retired cadre

\section{Acknowledgments}

The author thanks the Department of Pharmacy of the Second Affiliated Hospital of Chongqing Medical University to support this study's data collection.

\section{Authors' contributions}

$J L D$ and JJX drafted the paper and performed the main statistical analyses. DD supervised the study, reviewed the analysis, and revised the manuscript. All authors contributed to study design. Resources, YQ; data curation, XP and MYW; software, JY and WJH; All authors have read and agreed to the published version of the manuscript.

\section{Funding}

This research was funded by the Chongqing Basic Research and Frontier Exploration Project of Chongqing Natural Science Foundation (cstc2018jcyjA0135). The funding bodies had no role in the design of the study, data collection, analysis, interpretation of the data, and writing of the manuscript.

\section{Availability of data and materials}

The data that support the findings of this study are available from the Second Affiliated Hospital of Chongqing Medical University but restrictions apply to the availability of these data, which were used under license for the current study, and so are not publicly available. Data are however available from the authors upon reasonable request and with permission of the Second Affiliated Hospital of Chongqing Medical University.

\section{Declarations}

Ethics approval and consent to participate

Not applicable. This manuscript does involve the use of any animal or human data or tissue.

\section{Consent for publication}

Not applicable.

\section{Competing interests}

The authors declare no conflict of interest. This study has no financial relationship with any organization that sponsored the research and authorship.

\section{Author details}

${ }^{1}$ School of Public Health and Management, Chongqing Medical University, Chongqing, China. ${ }^{2}$ Sichuan Tianfu New Area Center for Disease Control and Prevention, Chengdu, Sichuan, China. ${ }^{3}$ Department of Pharmacy, The Second Affiliated Hospital of Chongqing Medical University, Chongqing, China.

Received: 28 October 2020 Accepted: 19 April 2021

Published online: 29 April 2021

\section{References}

1. Zheng G, Zhen L, Yang A, Yang Y, Chen L. Analysis on the origins of canceling drugs addition policy. Chinese Health Economics. 2015;34(02):3740. https://doi.org/10.7664/CHE20150208.

2. Wang J, Li P, Wen J. Impacts of the zero mark-up drug policy on hospitalization expenses of COPD inpatients in Sichuan province, western China: an interrupted time series analysis. BMC Health Serv Res. 2020;20(1): 1-8. https://doi.org/10.1186/s12913-020-05378-0.

3. Zhao $X$. Research on the effect of eliminating drug addition on medical expenses-taking Henan provincial hospital as an example. Master: Zhengzhou University; 2018.

4. Shao J, Shen H. Some views about the high cost of medical care in China Southeast Asian J Trop Med Public Health. 2010;41(1):240-162. https://doi. org/10.1111/j.1467-9566.2009.01213.x.

5. Fu H, Li L, Yip W. Intended and unintended impacts of price changes for drugs and medical services: evidence from China. Soc Sci Med. 2018:211: 114-22. https://doi.org/10.1016/j.socscimed.2018.06.007.

6. Deng J, Tian H, Guo Y, Ma T, Sun Y, Zhang S, et al. A retrospective and prospective assessment of the zero-markup drug reform in China from the perspective of policy diffusion. Int J Health Plann Manag. 2018;33(4):e91829. https://doi.org/10.1002/hpm.2562.

7. Luan M, Shao X, Dou F. Financial conditions, health care provision, and patient outcomes: evidence from Chinese public hospitals. Econ Lett. 2020; 186:108876. https://doi.org/10.1016/j.econlet.2019.108876.

8. Yan K, Yang C, Zhang H, Ye D, Liu S, Chang J, et al. Impact of the zeromark-up drug policy on drug-related expenditures and use in public hospitals, 2016-2018: an interrupted time series study in Shaanxi. BMJ Open. 2020;10(11):e037034. https://doi.org/10.1136/bmjopen-2020-037034.

9. Arabyat RM, Nusair MB, Al-Azzam Sl, Alzoubi KH. Analysis of prevalence, risk factors, and potential costs of unnecessary drug therapy in patients with chronic diseases at the outpatient setting. Expert Review of Pharmacoeconomics \& Outcomes Research. 2020;20(1):125-32. https://doi. org/10.1080/14737167.2019.1612243.

10. Hasanzad M, Sarhangi N, Meybodi HRA, Nikfar S, Khatami F, Larijani B. Precision medicine in non communicable diseases. International Journal of Molecular and Cellular Medicine. 2019;8(Suppl1):1. https://doi.org/10.22088/ IJMCM.BUMS.8.2.1

11. WHO. World health statistics overview 2019: monitoring health for the SDGs, sustainable development goals: World Health Organization; 2019. 
12. PRC. Interpretation of guidelines for prevention and treatment of chronic diseases in China (2017-2025). Chinese Practical Journal of Rural Doctor. 2017;24(11):6-11. https://doi.org/10.3969/j.issn.1672-7185.2017.11.002.

13. Tang S, Zhu Y, Wang C. Study on optimization of drug welfare effects of patients with chronic diseases based on factor analysis. China Pharmacy. 2020;31(4):390-6. https://doi.org/10.6039/j.issn.1001-0408.2020.04.02.

14. Lee JT, Hamid F, Pati S, Atun R, Millett C. Impact of noncommunicable disease multimorbidity on healthcare utilisation and out-of-pocket expenditures in middle-income countries: cross sectional analysis. PLoS One 2015;10(7):e0127199. https://doi.org/10.1371/journal.pone.0127199.

15. Limwattananon C, Waleekhachonloet $O$. Access to and price trends of antidiabetic, antihypertensive, and antilipidemic drugs in outpatient settings of the universal coverage scheme in Thailand. PLoS One. 2019;14(2): e0211759. https://doi.org/10.1371/journal.pone.0211759.

16. Yin $X, X u$ Y, Man $X$, Liu L, Jiang $Y$, Zhao L, et al. Direct costs of both inpatient and outpatient care for all type cancers: the evidence from Beijing, China. Cancer Medicine. 2019;8(6):3250-60. https://doi.org/10.1002/cam4.21 84.

17. Du J, Wang $Y$, Chen $M$, Wang Z. Empirical analysis of the actual reimbursement of basic medical Insurance of Outpatient Services and Influencing Factors. Chinese Hospital Management. 2019:39(1):50-52,61.

18. Luo L, Luo L, Zhang X, He X. Hospital daily outpatient visits forecasting using a combinatorial model based on ARIMA and SES models. BMC Health Serv Res. 2017;17(1):469. https://doi.org/10.1186/s12913-017-2407-9.

19. Yuan L, Tong J, Yang W, Wu H, Lv Y, Duan G. Application of GM $(1,1)$ and Verhulst model in prediction of outpatient and emergency of tertiary hospitals. Hospital Administration Journal of Chinese People's Liberation Army. 2019;26(2):138-41. https://doi.org/10.16770/J.cnki.1008-9985.2019.02. 011.

20. Liu J, Du W, Liu F. Study of the influence from regulation of drug-cost proportion control on the growth medical expenditure:an empirical analysis from China. Science-Technology and Management. 2018;20(3):63-9. https:// doi.org/10.16315/j.stm.2018.03.005.

21. Pan L, He P, Wu H, Deng Y, Zhang W, Pan C. Medical expenses of outpatients and inpatients in a municipal public hospital and the mode of payment. Chinese General Practice. 2014;34:4127-32. https://doi.org/10.3 969/j.issn.1007-9572.2014.34.028.

22. Cao $\mathrm{S}$, Chen $\mathrm{X}$. A brief analysis of the change of outpatient service quantity and income structure after deepening medical reform. China Health Standard Management. 2020;11(7):40-2. https://doi.org/10.3969/j.issn.16749316.2020.07.014.

23. Yang C, Shen Q, Cai W, Zhu W, Li Z, Wu L, et al. Impact of the zero-markup drug policy on hospitalisation expenditure in western rural China: an interrupted time series analysis. Tropical Med Int Health. 2017;22(2):180-6. https://doi.org/10.1111/tmi.12817.

24. Box GE, Tiao GC. Intervention analysis with applications to economic and environmental problems. J Am Stat Assoc. 1975;70(349):70-9. https://doi. org/10.1080/01621459.1975.10480264

25. Wagner AK, Soumerai SB, Zhang F, Ross-Degnan D. Segmented regression analysis of interrupted time series studies in medication use research. J Clin Pharm Ther. 2002;27(4):299-309. https://doi.org/10.1046/j.1365-2710.2002. 00430.x.

26. McKirdy A, Imbuldeniya A. The clinical and cost effectiveness of a virtual fracture clinic service: an interrupted time series analysis and before-andafter comparison. Bone \& Joint Research. 2017;6(5):259-69. https://doi.org/1 0.1302/2046-3758.65.bJr2017-0330.r1.

27. Wang Y, Zhu Y, Shi H, Sun X, Chen N, Li X. The effect of the full coverage of essential medicines policy on utilization and accessibility of primary healthcare service for rural seniors: a time series study in Qidong, China. Int J Environ Res Public Health. 2019;16(22):4316. https://doi.org/10.3390/ijerph1 6224316.

28. Zhu X, Lin T, Mi Y, Hu M. Interrupted time series model and its application in effect evaluation of health policy intervention. Chinese Pharmaceutical Affairs. 2018;32(11):1531-40. https://doi.org/10.16153/j.1002-7777.2018.11. 013.

29. Zhang WY, Li YR, Li YJ, Li XQ, Zhao WG, Lu RZ. A cross-sectional analysis of prescription and stakeholder surveys following essential medicine reform in Guangdong Province, China. BMC Health Services Research. 2015;15(1):7. https://doi.org/10.1186/s12913-015-0778-3.

30. Wang J, Liu X, Wang S, Chen H, Wang X, Zhou W, et al. Short-term differences in drug prices after implementation of the national essential medicines system: a case study in rural Jiangxi Province, China. Indian Journal of Pharmacology. 2015;47(5):535-9. https://doi.org/10.4103/02537613.165192.

31. Chao J, Gu J, Zhang H, Chen H, Wu Z. The impact of the national essential medicines policy on rational drug use in primary care institutions in Jiangsu Province of China. Iran J Public Health. 2018;47(1):24-32.

32. Niu W, Huang J, Xing Z, Chen J. Knowledge spillovers of medical big data under hierarchical medical system and patients' medical treatment decisions. IEEE Access. 2019;7:55770-9. https://doi.org/10.1109/access.2019.2 908440.

33. Zhou Z, Zhao Y, Shen C, Lai S, Nawaz R, Gao J. Evaluating the effect of hierarchical medical system on health seeking behavior: a difference-indifferences analysis in China. Soc Sci Med. 2020;268:113372. https://doi.org/1 0.1016/j.socscimed.2020.113372.

34. Ai W. Participatory action research into low literates' medical needs in rural communities. SciMedicine Journal. 2019;1(4):176-88. https://doi.org/10.2 8991/SciMedJ-2019-0104-3.

35. Wang T, Yu B, Yang F. Analysis of hospitalization cost and length of stay of patients with different medical insurance types of diabetes. Health Economics Research. 2013;2:52-3. https://doi.org/10.3969/j.issn.1004-7778.2 013.02.018.

36. Wang J. Research on the influence of zero-profit drugs sales policy to the patient personal burden _- in the TianJin BinHai new area as an example. Master: Hebei United University; 2015.

\section{Publisher's Note}

Springer Nature remains neutral with regard to jurisdictional claims in published maps and institutional affiliations.

\section{Ready to submit your research? Choose BMC and benefit from:}

- fast, convenient online submission

- thorough peer review by experienced researchers in your field

- rapid publication on acceptance

- support for research data, including large and complex data types

- gold Open Access which fosters wider collaboration and increased citations

- maximum visibility for your research: over $100 \mathrm{M}$ website views per year

At BMC, research is always in progress.

Learn more biomedcentral.com/submissions 